\title{
Microwave Emission and Scattering from Ocean Surface Waves in the Southern Beaufort Sea
}

\author{
Mukesh Gupta, Randall K. Scharien, and David G. Barber \\ Department of Environment and Geography, Wallace Building, Centre for Earth Observation Science, \\ Clayton H. Riddell Faculty of Environment, Earth, and Resources, University of Manitoba, Winnipeg, MB, Canada \\ Correspondence should be addressed to Mukesh Gupta; guptm@yahoo.com
}

Received 24 December 2013; Accepted 31 January 2014; Published 10 March 2014

Academic Editor: Heinrich Hühnerfuss

Copyright (C) 2014 Mukesh Gupta et al. This is an open access article distributed under the Creative Commons Attribution License, which permits unrestricted use, distribution, and reproduction in any medium, provided the original work is properly cited.

\begin{abstract}
Estimates of the relationships between geophysical variables and microwave backscatter/emission are important for the evaluation of atmosphere-ocean interaction, as well as energy, and mass transfer across this interface. We evaluate ship-based passive microwave brightness temperatures $\left(T_{b}\right)$ at 37 and $89 \mathrm{GHz}$ and active polarimetric backscatter at $5.5 \mathrm{GHz}(\mathrm{C}$-band), as these relate to buoy-derived ocean wave parameters for distinct wave regimes in the southern Beaufort Sea. Microwave emission and backscatter are shown to be sensitive to the ocean surface physical roughness as defined by the significant wave height $\left(H_{m 0}\right)$, compared to wind speed. The $T_{b}$ shows significant correlation with $H_{m 0}$, with the strongest correlation for the H-polarization channel at 37 and $89 \mathrm{GHz}$. Active co- $\left(\gamma_{\mathrm{co}}\right)$ and cross- $\left(\gamma_{\text {cross }}\right)$ polarization ratios at $40^{\circ}$ incidence angle are associated with $H_{m 0}$, with the $\gamma_{\mathrm{co}}$ increase proportional to $H_{m 0}$. The polarimetric coherence parameter $\rho_{\mathrm{VvHH}}$ at $20^{\circ}$ also shows an inverse relationship with $H_{m 0}$ because of an expected decorrelation of complex returns with greater surface roughness.
\end{abstract}

\section{Introduction}

The southern Beaufort Sea is of interest because of its dynamic seasonal ocean-sea ice-atmosphere interaction $[1$, 2] and the seasonal formation of flaw leads and polynyas $[3,4]$. Microwave remote sensing has played a key role in investigations, with scientists studying the passive and active microwave signatures from the ocean surface for several decades. It has now been possible to estimate numerous geophysical parameters with sufficient accuracy based on microwave data collected using satellite sensors. However, relationship between surface waves and the radiative transfer across the atmosphere-ocean ( $\mathrm{AO}$ ) interface is, yet, not fully realized in the literature.

Ocean surface waves modify AO interaction and concurrently affect observed passive microwave brightness temperatures $\left(T_{b}\right)$ and radar returns (hereinafter backscatter). Enhanced surface roughness from wind-generated surface waves significantly affects the formation and evolution of the oceanic boundary layer [5], which in turn causes greater atmospheric instability and turbulent exchange at the $\mathrm{AO}$ interface [6]. Physical roughness also acts as an important component of feedback processes which transfer heat and momentum across AO interface. Though there is good understanding of the transfer of wind energy to the ocean surface waves (aerodynamic roughness), the microwave behavior of related geophysical variables such as significant wave height $\left(H_{m 0}\right)$ (hereinafter wave height), power spectral density (PSD), ocean surface temperature, and near-surface water vapor is the subject of further study. Open water backscatter and $T_{b}$ observations represent composite signals that contain contributions from the full suite of these variables. In accordance, the application of electromagnetic (EM) signatures to geophysical inversion algorithms first demands consideration of the full suite of variables.

Previous research into AO surface roughness from both passive and active microwave remote sensing indicates considerable gaps in understanding the EM response to roughness elements (e.g., whitecaps, sea spray, and wave RMS (root mean square) height and correlation length). Polarimetric passive microwave signatures of the ocean surface at frequencies $10.7,19.35$, and $37 \mathrm{GHz}$ are well modeled by a two-scale polarimetric emission model $[7,8]$; however, the assimilation of effects of wind direction, wind-generated waves, atmospheric stability, and sea foam into polarimetric emission models of ocean surface is a topic requiring further research. 
The undulations of the ocean surface significantly affect the observed, frequency-dependent, $T_{b}$, which is dependent on the wind-induced wave structure, that is, the sea state and foam coverage $[9,10]$. Kravtsov and Churyumov [11] mathematically delineated the effect of steep irregularities and wave slope on the $T_{b}$. Monahan and O'Muircheartaigh [12] used remote sensing to include whitecaps and foam in the wind retrieval algorithms. Wave height can also be linked to $T_{b}$ as a close function of surface wind speed [13]. Nordberg et al. [14] provided the measurements of microwave emission at $19 \mathrm{GHz}$ from a foam-covered and wind-driven sea. One observes an increase in the $T_{b}$ with an increase in foam coverage and whitecaps in all surface conditions mentioned above.

Microwave C-band $(5.5 \mathrm{GHz}, \quad 5.6 \mathrm{~cm}$ wavelength) backscatter is more reliable for studying ocean surface waves than shorter wavelength $\mathrm{Ku}-$, Ka-, and X-bands. Capillarity and molecular viscosity (water temperature) strongly influence the radar return in these bands $[15,16]$. There are numerous studies readily found on relationships between C-band copolarization backscatter ( $\mathrm{HH}$ and VV) and wind speed and direction, with geophysical model transfer functions (e.g., CMOD) widely used to retrieve wind information from backscatter [17-20]. A power-law relationship holds for backscatter and friction velocity [21] and between backscatter and wind speed [22]. Keller et al. [22] also observed backscatter increasing with decreasing AO temperature difference. Thompson et al. [23] found that the observed copolarization ratio $(\mathrm{HH} / \mathrm{VV})$ is larger than predicted by backscatter models, as these models inadequately address the nonlinearity of the long-wave portion of a rough ocean surface. Thompson et al. [23] provided an incidence-angle-dependent polarization ratio model. Mouche et al. [24] extended this model to include wind speed, wind direction, sea state, and swell effects. The results of Mouche et al. [24] show that the copolarization ratio $\left(\gamma_{c o}\right)$ is dependent more on wave steepness than on wave height and wind speed.

The waves under rough conditions are typically 3-10 times larger than the incident radar wavelength at C-band $[25,26]$. Kudryavtsev et al. [25] suggested a composite backscatter model for describing backscatter (at moderate incidence angles $20^{\circ}-60^{\circ}$ ) from ocean surface waves which included non-Bragg scattering components caused by breaking waves (wavelength from few millimeters to few meters) based on wave breaking statistics proposed by Phillips [27]. One can use the $\gamma_{c o}$ to study the discrepancy between the Bragg model and observations, and it can explain the nonBragg component of scattering [25]. Valenzuela [28] provided a review of the theories addressing EM wave interaction with the small gravity-capillary waves, citing Bragg (resonant) scattering as the most important mechanism of ocean surface-EM interaction. Energy dissipation over different length scales and breaking wave mechanisms is largely linked to non-Bragg scattering, though there is little understanding of their effects on backscatter. The $H_{m 0}$ and wave PSD measured from Waverider buoy are investigated here, which contain contributions from the non-Bragg scattering elements, using the cross-polarization channel ratio $\left(\gamma_{\text {cross }}\right)$ and polarimetric coherence parameters, in addition to $\gamma_{\mathrm{co}}$.

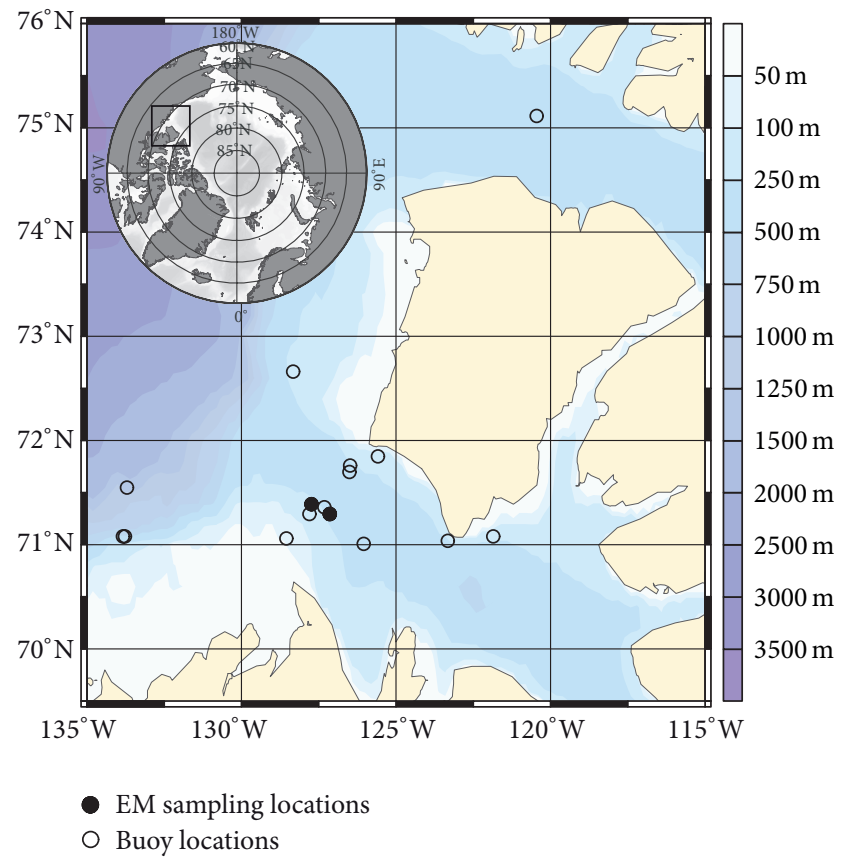

FIgURE 1: Study area showing DWR-G4 buoy and EM sampling locations.

This paper addresses open ocean surface waves (physical roughness) during the ice-free season, with the overarching objective, to further our understanding of the role of $T_{b}$ and backscatter in estimating ocean surface waves and, by proxy, $\mathrm{AO}$ exchanges. We examine near surface (ship-based) passive microwave $T_{b}(37$ and $89 \mathrm{GHz}$ ) and polarimetric Cband backscatter, as these relate to buoy measurements of $H_{m 0}$ and PSD. This comparison is rarely available in the literature. We investigate the utility of $\gamma_{\text {co }}$ and $\gamma_{\text {cross }}$, as well as polarimetric coherences from the ocean surface, to contribute to the realization of polarimetric synthetic aperture radar for deriving ocean surface wave information.

\section{Materials and Methods}

2.1. Study Area. The study area lies in Amundsen Gulf in the southern Beaufort Sea (Figure 1). The Cape Bathurst Polynya forms in the area and hosts several flaw leads throughout the winter [1] and the region becomes ice-free in the summer. We acquired field data between July 1 and 28, 2008 under the auspices of the Circumpolar Flaw Lead (CFL) System Study, an International Polar Year (IPY) project that took place between October 2007 and August 2008 aboard the Canadian Research Icebreaker Amundsen [29].

2.2. Instruments' Description and Data Collection. We acquired ocean wave height, wave steepness, wave period, and wave phase speed using a meteorological ocean (Datawell, Haarlem, The Netherlands) Mini Directional Waverider G4 (DWR-G4) buoy. The buoy has a hull diameter of $0.4 \mathrm{~m}$ and weight in air of $17 \mathrm{~kg}$. The buoy is capable of measuring wave height and direction for periods of 
TABLE 1: Technical properties and specifications of C-band scatterometer used.

\begin{tabular}{ll}
\hline System parameter & Value \\
\hline RF output & $5.25-5.75 \mathrm{GHz}$ \\
Antenna diameter & $0.61 \mathrm{~m}$ \\
Transmit bandwidth & $5-500 \mathrm{MHz}$, user adjustable \\
Range resolution & $0.3-30.0$ meters, user adjustable \\
Antenna beamwidth & $\mathrm{H}-$ pol: $5.2^{\circ}$ azimuth, $5.5^{\circ}$ elevation \\
Antenna gain & V-pol: $5.6^{\circ}$ azimuth, $5.3^{\circ}$ elevation \\
Cross-polarization isolation & $28 \mathrm{~dB}$, nominal \\
Transmit/receive polarizations & $>30 \mathrm{~dB}$, measured at the peak of the beam \\
Sensitivity, minimum NRCS at $15 \mathrm{~m}$ range & Linear, vertical, and horizontal \\
Chirp length & $-40 \mathrm{~dB} \mathrm{~m}^{2} / \mathrm{m}^{2}$ \\
\hline
\end{tabular}

Note. NRCS: normalized radar cross-section; RF: radio frequency.

1.6-100 sec and covers the expected range of wave periods observed in the Arctic ( $60 \mathrm{sec}$; see, e.g., [30]). Wave height accuracy is $1 \mathrm{~cm}$ in all directions while freely floating. We computed $H_{m 0}$ from the zeroth moment of the wave spectrum. The accuracy of wave PSD, wavelength, and other derived wave parameters relies on wave height accuracy. We deployed the buoy by small boat at a minimum distance of $200 \mathrm{~m}$ to avoid interference by the Amundsen. Wave data were logged at 30-minute intervals from a stabilized accelerometer. We collected continuous meteorological data at one-minute interval from a tower mounted on the bow of the Amundsen. An RM-Young model 5103 Wind Monitor provided the wind speed $(U)$ data at $14 \mathrm{~m}$ above sea level (ASL) at accuracy of $\pm 0.3 \mathrm{~m} / \mathrm{s}$ or $1 \%$ of the reading. The Amundsen's AXYS Automated Voluntary Observing Ship (AVOS) sensors provided water temperature at the sea surface with a resolution of $0.1^{\circ} \mathrm{C}$ and an accuracy of $\pm 0.3^{\circ} \mathrm{C}$.

We have used ship-based dual-polarized ( $\mathrm{H}$ and $\mathrm{V}$ ) passive microwave (Radiometrics, Boulder, CO, USA) radiometers operating at 37 and $89 \mathrm{GHz}$ frequencies to acquire emissions at a fixed incidence angle of $53^{\circ}$, the same angle as the spaceborne SSM/I (Special Sensor Microwave/Imager) sensor and within $2^{\circ}$ of the spaceborne AMSR-E (Advanced Microwave Scanning Radiometer-Earth Observing System) sensor. We installed the system on the rail mount on the port side of the Amundsen at approximately $12 \mathrm{~m}$ ASL. To convert recorded voltages to $T_{b}$, we followed the calibration method described by Farmer et al. [31]. The $T_{b}$ data were acquired for 24-hour full cycle for all days and were averaged for every 30 minutes for the specified dates during the month of July 2008 at the locations shown in Figure $1 . T_{b}$ data were matched with buoy data over 2-7 hours duration for comparison in this study. This paper presents the relationships of $H_{m 0}$ and PSD and ship-based $T_{b}$ at meter scales (footprint at $89 \mathrm{GHz}$ at $55^{\circ}: 6.36 \mathrm{~m}^{2}$; at $\left.37 \mathrm{GHz}: 6.62 \mathrm{~m}^{2}\right)$ at $0.81 \mathrm{~cm}(37 \mathrm{GHz})$ and $0.34 \mathrm{~cm}(89 \mathrm{GHz})$ wavelengths.

We have used a C-band fully polarimetric scatterometer (ProSensing Inc., Amherst, MA, USA) (Table 1) installed on the port side of the Amundsen at a height of $7.6 \mathrm{~m} \mathrm{ASL}$ to collect backscatter signatures coincident to ocean buoy data over short ( $<0.5$ hour) periods on 1, 9, and 26 of July. We collected backscatter and phase data at all four linear transmit/receive polarization combinations $(\mathrm{HH}, \mathrm{HV}, \mathrm{VH}$, and $\mathrm{VV}$ ) over the $20^{\circ}-60^{\circ}$ incidence angle range at $10^{\circ}$ spacing and across a $60^{\circ}$ azimuth centered perpendicular to the Amundsen. At $7.6 \mathrm{~m}$ height, and with the scatterometer positioned at a fixed azimuth and $45^{\circ}$ incidence angle, its estimated footprint was $1.1 \mathrm{~m}^{2}$. A single scan comprised several resolution cells over several meters by extending the azimuth to a $60^{\circ}$ range, resulting in multiple statistically independent samples of the sea surface at each incidence angle. The use of a wide azimuth also increased the number of radar looks and reduced fading, though the resulting experimental dataset does not consider the wave direction relative to the scanning scatterometer. Isleifson et al. [32] and Geldsetzer et al. [33] have described the instrument calibration, noise levels, setup, and data limitations.

We placed a limit of $3 \mathrm{~dB}$ of signal-to-noise ratio on backscatter for analysis of scatterometer data, resulting in an upper incidence angle limit of $40^{\circ}$ for scans taken during calm conditions. This limit extends to all samples to enable the intercomparison of all backscatter irrespective of sea state. The average covariance matrix, from which we derive $\mathrm{HH}, \mathrm{HV}$, and VV backscatter, as well as $\gamma_{\text {co }}$ and $\gamma_{\text {cross }}$, using backscatter amplitudes, represents the scan data. We obtained the following polarimetric coherence parameters: the copolarized correlation coefficient $\left(\rho_{\mathrm{VVHH}}\right)$; the crosspolarized correlation coefficient $\left(\rho_{\mathrm{HHVH}}\right)$; and the coherence of right and left circular transmit/receive polarizations $\left(\rho_{\mathrm{RRLL}}\right)$ using the following formulae [34-36]:

$$
\begin{aligned}
& \rho_{\mathrm{VVHH}}=\frac{\left\langle\left|S_{\mathrm{VV}} S_{\mathrm{HH}}^{*}\right|\right\rangle}{\sqrt{\left\langle\left|S_{\mathrm{VV}}\right|^{2}\right\rangle\left\langle\left|S_{\mathrm{HH}}\right|^{2}\right\rangle}}, \\
& \rho_{\mathrm{HHVH}}=\frac{\left\langle\left|S_{\mathrm{HH}} S_{\mathrm{VH}}^{*}\right|\right\rangle}{\sqrt{\left\langle\left|S_{\mathrm{HH}}\right|^{2}\right\rangle\left\langle\left|S_{\mathrm{VH}}\right|^{2}\right\rangle}},
\end{aligned}
$$




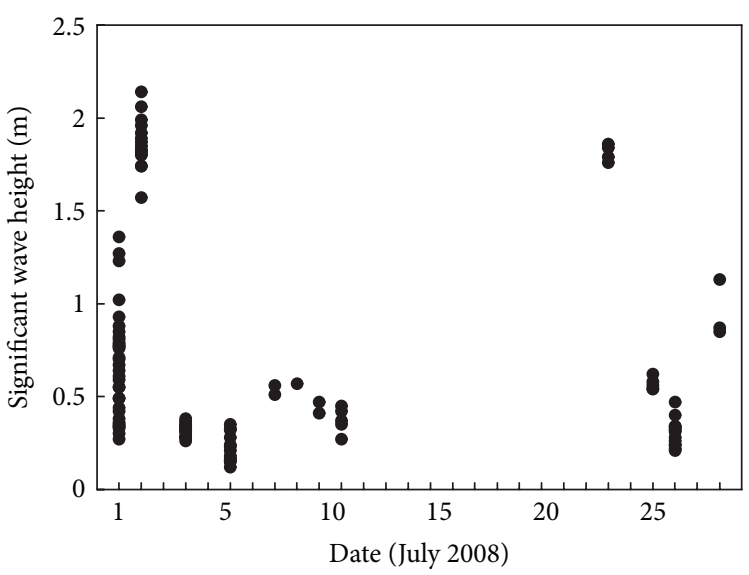

(a)

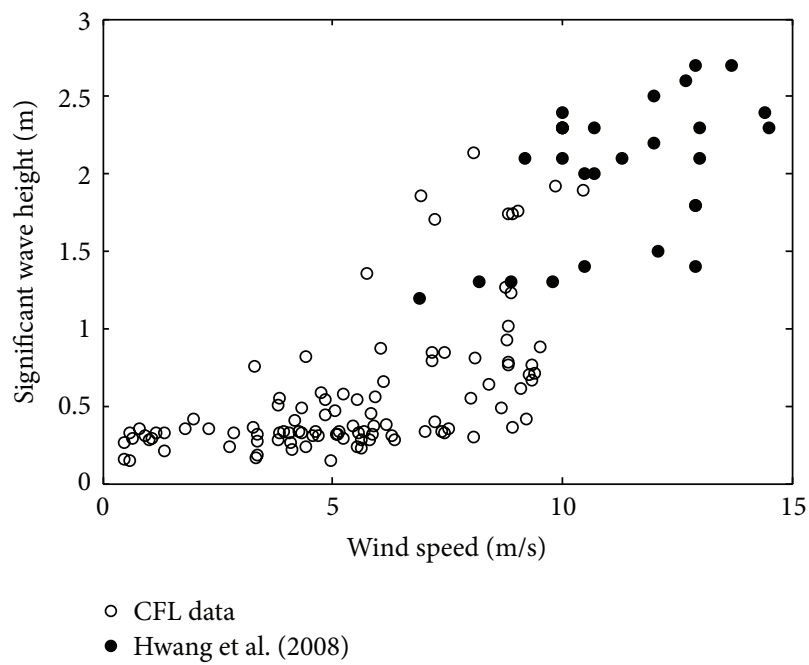

(b)

FiguRE 2: (a) Significant wave height $\left(H_{m 0}\right)$ observed from July 1 to 28, 2008 (total number of samples = 103). Multiple measurements on a day fall on the same vertical line. (b) $H_{m 0}$ is plotted versus wind speed and compared with data (total number of samples $=29$ ) from Hwang et al. [40].

$$
\begin{gathered}
\rho_{\mathrm{RRLL}}=\frac{\left\langle\left|S_{\mathrm{HH}}-S_{\mathrm{VV}}\right|^{2}\right\rangle-4\left\langle\left|S_{\mathrm{HV}}\right|^{2}\right\rangle}{\left\langle\left|S_{\mathrm{HH}}-S_{\mathrm{VV}}\right|^{2}\right\rangle+4\left\langle\left|S_{\mathrm{HV}}\right|^{2}\right\rangle}, \\
\gamma_{\mathrm{co}}=\frac{S_{\mathrm{VV}}}{S_{\mathrm{HH}}}, \quad \gamma_{\text {cross }}=\frac{S_{\mathrm{HV}}}{S_{\mathrm{HH}}}
\end{gathered}
$$

where $S$ is the complex scattering matrix and an asterisk $\left({ }^{*}\right)$ represents the complex conjugate. The brackets $\langle\cdot\rangle$ represent ensemble averages of the observed data. Polarimetric coherences and polarization ratios have demonstrated utility in reducing the ambiguities caused by the nonlinearity between system response and target properties [37]. Further details on the derivation of $\rho_{\text {RRLL }}$, a parameter shown to be sensitive to surface roughness, are available in $[38,39]$.

\section{Results and Discussion}

3.1. Ocean Surface Wave Conditions. The data primarily represent wave breaking and energy dissipation of waves depending on the prevailing wind conditions. From the measured buoy data, $H_{m 0}$ ranged between 12 and $214 \mathrm{~cm}$ (sea state on Beaufort scale $0-5$ ) compared to those by Hwang et al. [40] who reported a range of $120-270 \mathrm{~cm}$ in the Atlantic Ocean (Figure 2). Observed wave numbers ranged between 0.083 and $0.729 \mathrm{rad} / \mathrm{m}$, and the wind speeds ranged between 0.5 and $10.5 \mathrm{~m} / \mathrm{s}$ compared to wind speed range of $7.0-14.5 \mathrm{~m} / \mathrm{s}$ given by Hwang et al. [40]. The wave steepness, in this paper, ranged between 0.011 and 0.050 , which corresponded with the wavelength ranging between 8.61 and $75.56 \mathrm{~m}$. The wave periods of wind-generated waves addressed in this paper lie between 2.4 and $7.0 \mathrm{sec}$. We did not observe swells (wave period $>10 \mathrm{sec}$ [41]) during the field program. The observed relationship between the nondimensional form of energy,

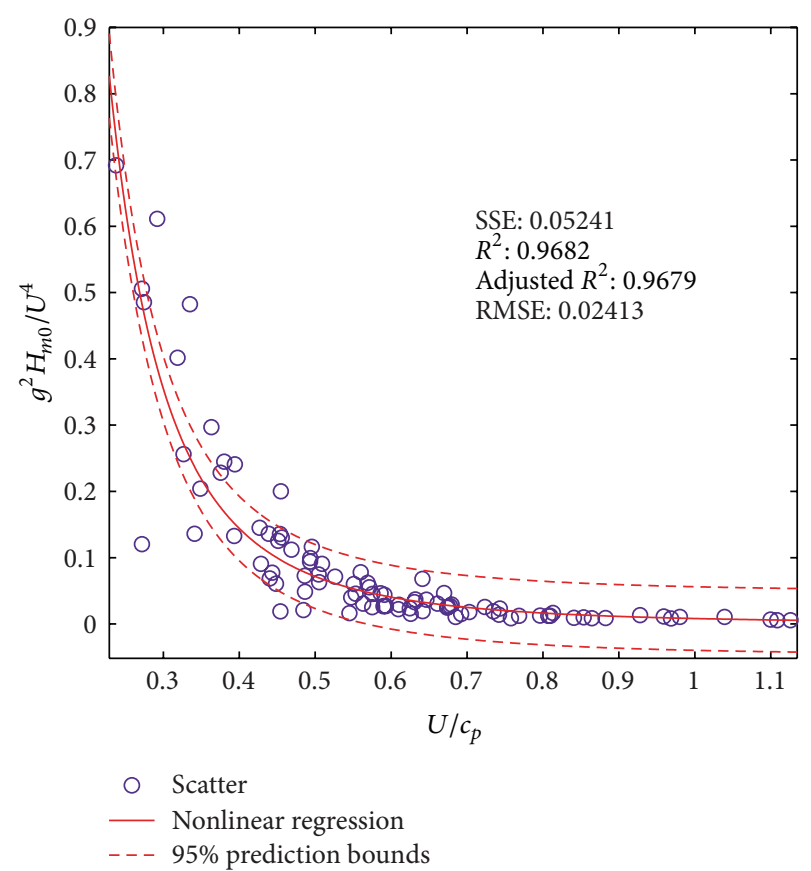

FIgURE 3: The plot shows the wind-generated wave condition in the experiment. Nonlinear model $y=a x^{b}$ between nondimensional wave energy ( $y$-axis) and wave age ( $x$-axis) indicates wind-induced wave development. SSE is the sum of squared error of the fit.

$g^{2} H_{m 0} / U^{4}$ (where $g$ is gravitational acceleration), and wave age, $U / c_{p}$ (where $c_{p}$ is wave phase speed), as initially proposed by Kitaigorodskii [42] and further developed by Donelan et al. [43], supports the wind-generated wave growth in the data (Figure 3). The RMS error in the fitted curve is 0.024 ; the 
TABLE 2: Scatterometer measurement dates and times, sampling durations, near and far range numbers of independent samples ( $\left.n_{\text {ind }}\right)$ of the sea surface, with coincident wind speed, wave roughness parameters, significant wave height $\left(H_{m 0}\right)$, and power spectral density (PSD).

\begin{tabular}{lccccccc}
\hline Date $(2008)$ & Time (UTC) & Duration (minutes) & Radar $n_{\text {ind }}$ (near) & Radar $n_{\text {ind }}($ far) & Wind speed $(\mathrm{m} / \mathrm{s})$ & Wave PSD $\left(\mathrm{m}^{2} / \mathrm{Hz}\right)$ & Wave $H_{m 0}(\mathrm{~cm})$ \\
\hline July 1 & $18: 37$ & 14 & 44 & 122 & 7.4 & 4.3154 & 136 \\
July 9 & $16: 57$ & 17 & 44 & 122 & 5.8 & 0.2787 & 66 \\
July 26 & $17: 49$ & 24 & 66 & 198 & 3.9 & 0.4617 \\
\hline
\end{tabular}

Note. UTC: Universal Time Coordinated.

TABLE 3: Correlation matrix (Pearson's $r$ ) of observed variables. The number of samples of each variable is 111.

\begin{tabular}{lccccccc}
\hline & $T_{b} 89 \mathrm{H}$ & $T_{b} 89 \mathrm{~V}$ & $T_{b} 37 \mathrm{H}$ & $T_{b} 37 \mathrm{~V}$ & $H_{m 0}$ & $T_{w}$ & \\
\hline$T_{b} 89 \mathrm{H}$ & 1 & & & & & & \\
$T_{b} 89 \mathrm{~V}$ & $\mathbf{0 . 9 3}$ & 1 & & & & \\
$T_{b} 37 \mathrm{H}$ & $\mathbf{0 . 9 7}$ & $\mathbf{0 . 8 8}$ & 1 & & & \\
$T_{b} 37 \mathrm{~V}$ & $\mathbf{0 . 8 5}$ & $\mathbf{0 . 9 1}$ & $\mathbf{0 . 8 7}$ & 1 & & \\
$H_{m 0}$ & $\mathbf{0 . 8 0}$ & $\mathbf{0 . 7 2}$ & $\mathbf{0 . 7 8}$ & 0.55 & 1 & \\
PSD & $\mathbf{0 . 7 1}$ & $\mathbf{0 . 6 4}$ & $\mathbf{0 . 7 0}$ & 0.52 & $\mathbf{0 . 9 2}$ & \\
$T_{w}$ & 0.25 & 0.44 & 0.16 & 0.21 & 0.25 & 0.20 & 1 \\
$U$ & 0.06 & -0.02 & 0.09 & -0.08 & 0.24 & 0.21 & 0.09 \\
\hline
\end{tabular}

Note: $T_{b} 89 \mathrm{H}$ : brightness temperature at $89 \mathrm{GHz} \mathrm{H}$-polarization $(\mathrm{K})$.

$T_{b} 89 \mathrm{~V}$ : brightness temperature at $89 \mathrm{GHz} \mathrm{V}$-polarization $(\mathrm{K})$.

$\mathrm{T}_{b} 37 \mathrm{H}$ : brightness temperature at $37 \mathrm{GHz} \mathrm{H}$-polarization (K).

$T_{b} 37 \mathrm{~V}$ : brightness temperature at $37 \mathrm{GHz} \mathrm{V}$-polarization $(\mathrm{K})$.

$H_{m 0}$ : significant wave height $(\mathrm{cm})$.

PSD: wave power spectral density $\left(\mathrm{m}^{2} / \mathrm{Hz}\right)$.

$T_{w}$ : water temperature $\left({ }^{\circ} \mathrm{C}\right)$

$U$ : wind speed $(\mathrm{m} / \mathrm{s})$.

Numerals in bold represent statistically significant correlation at the $95 \%$ confidence level.

coefficient of determination, $R^{2}=0.97$; and sum of residual errors, $\mathrm{SSE}=0.052$. The observed empirical relationship is

$$
\frac{g^{2} H_{m 0}}{U^{4}}=0.00817\left(\frac{U}{c_{p}}\right)^{-3.132} .
$$

Table 2 shows wave roughness parameters $H_{m 0}$ and PSD, coincident to scatterometer acquisitions on July 1, 9, and 26,2008 , along with $U$. While the scatterometer took eight minutes to complete one scan, wave height and PSD data were logged at 30 -minute intervals. Table 2 also provides a summary of independent scatterometer samples acquired at $20^{\circ}$ and $40^{\circ}$ incidence angles, the near and far ranges examined in this study. Figure 4 shows the wave spectra from the same dates relative to the analytical Pierson-Moskowitz (P-M), Bretschneider, and 3-parameter Gamma wave spectra. These wave spectra considered both capillary and gravity wave (wavelength $>1.74 \mathrm{~cm}$ ) development. The observed spectra is in agreement with the modeled spectra for the $H_{m 0}$ case on July 9, with peak frequencies of $\sim 0.2 \mathrm{~Hz}$. The observed spectra agree more closely with the $\mathrm{P}-\mathrm{M}$ model at wave frequency greater than $0.2 \mathrm{~Hz}$ for other $H_{m 0}$ cases. The $H_{m 0}$ cases also contain more observed wave energy in the low frequency part of the observed spectra, indicating the presence of longer waves. The low frequency (larger waves) part of the spectra is marginally modeled by the wave spectra models, likely because of insufficient number of statistical data points of long wavelength waves available to generate a spectrum that fits the analytical spectrum. Also, the data lacked the longer wavelength waves or swell observations. Therefore, we consider only the wave frequencies of $0.2 \mathrm{~Hz}$ and above in the present treatment. The high $H_{m 0}$ at low wind speeds indicates that the wave energy still retained in the ocean even after winds have subsided. This transition from calm to rough sea (and vice versa) depends on the rate of wave energy dissipation in the ocean (Figures 2 (b) and 4). These observed wave conditions set the background for which we investigate the microwave signatures of ocean surface in the next section.

3.2. Comparison to Passive and Active Microwave Signatures. Table 3 shows the linear associations between geophysical variables $\left(H_{m 0}, \mathrm{PSD}\right.$, water temperature, and $\left.U\right)$ and $T_{b}$ at 37 and $89 \mathrm{GHz}$ as a correlation matrix. We observed a low probability value $(P$ value $<0.05)$ for each combination of bolded variables given in Table 3 , verifying statistical significance. Table 4 provides the regression coefficients for estimating the $H_{m 0}$ using $T_{b}$ and Figure 5 shows pertinent regression relationships. Wind speed does not correlate with $T_{b}$; however, we observe that $T_{b}$ at $37 \mathrm{GHz}$ and $89 \mathrm{GHz}$ shows significant correlation with the $H_{m 0}$ and the PSD of the waves and the correlation is stronger for $\mathrm{H}$-polarization than V-polarization. Thus, the higher $T_{b} \mathrm{H}$-polarization implies an indirect contribution of wind energy in inducing wave heights than V-polarization. We did not observe any linear relationships between water surface temperature and $T_{b}$. Besides this, several other external factors that alter the 
TABLE 4: Regression coefficients for $H_{m 0}$ and $T_{b}$ for various frequencies and polarizations. The fitted line is $T_{b}=a+b H_{m 0}$. Each regression contained 124 samples. We observed statistically significant linear regression for each frequency and polarization, with good correlation of $T_{b}$ at H-polarization of $89 \mathrm{GHz}$ with $H_{m 0}$.

\begin{tabular}{lccccc}
\hline & $a$ & $b$ & $P$ value $(95 \%$ confidence interval) & Lower and upper bounds for $b$ & Pearson's $r$ \\
\hline $89 \mathrm{H}$ & 173.98 & 0.15 & $<0.001$ & $0.13,0.18$ \\
$89 \mathrm{~V}$ & 240.00 & 0.04 & $<0.001$ & $0.03,0.05$ \\
$37 \mathrm{H}$ & 120.60 & 0.10 & $<0.001$ & $0.08,0.12$ \\
$37 \mathrm{~V}$ & 201.51 & 0.03 & $<0.001$ & $0.02,0.03$ & 0.65 \\
\hline
\end{tabular}

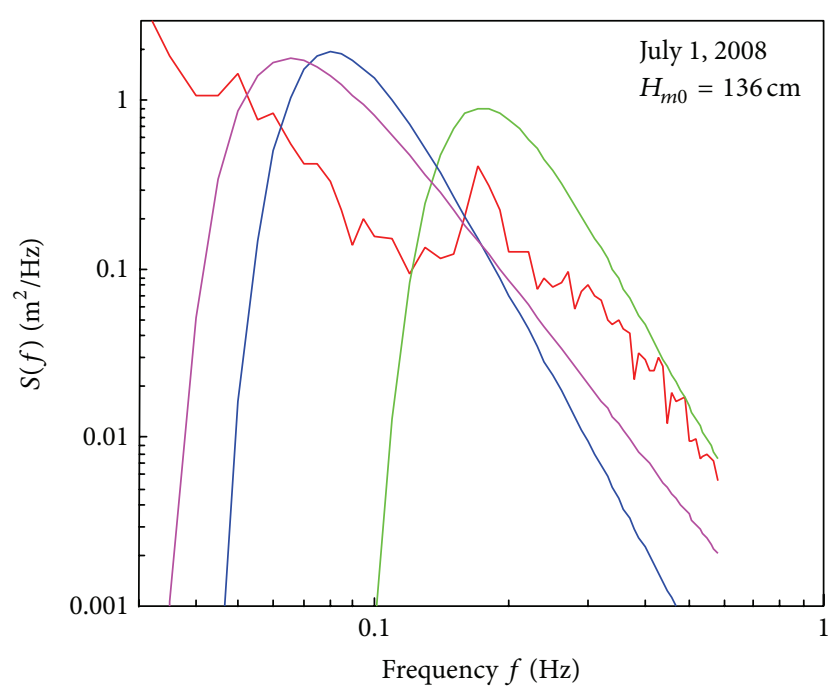

$\begin{array}{ll}\text { Measured } & \text { Bretschneider } \\ - \text { Pierson-Moskowitz } \quad \text { 3-parameter Gamma }\end{array}$

(a)

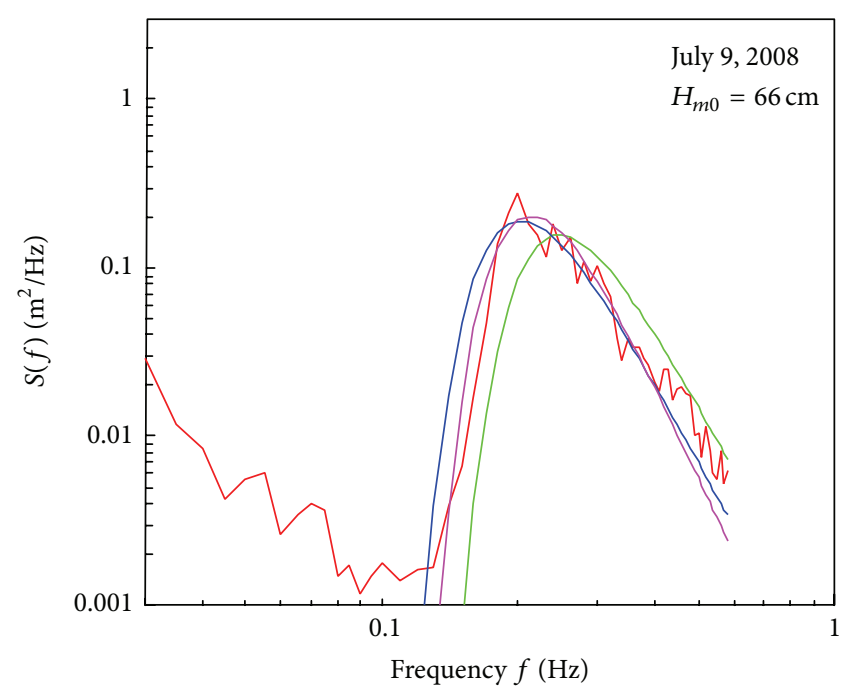

$\begin{array}{ll}\text { - Measured } & \text { Bretschneider } \\ \text { Pierson-Moskowitz } & \text { 3-parameter Gamma }\end{array}$

(b)

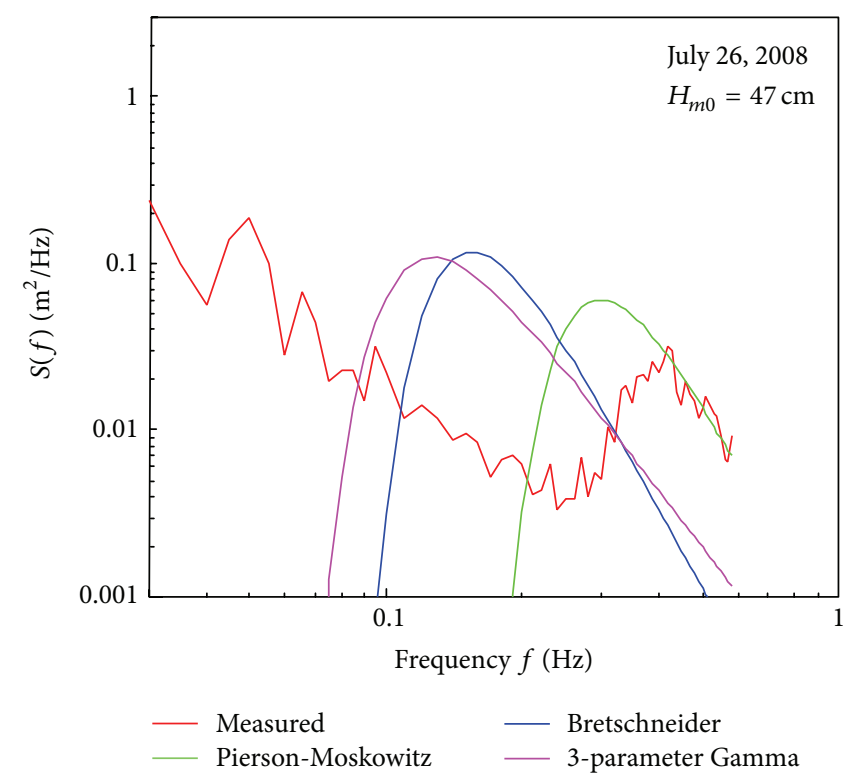

(c)

FIgURE 4: The wave spectra measured coincident to scatterometer on July 1, 9, and 26, 2008 with comparisons to analytical spectra. Red: measured; green: Pierson-Moskowitz; blue: Bretschneider; magenta: 3-parameter Gamma. 


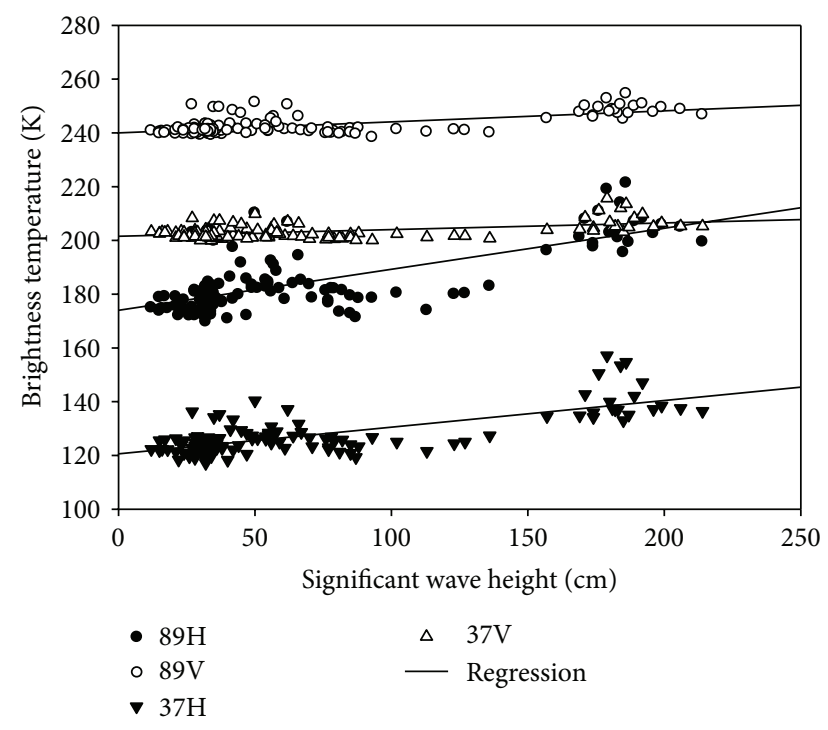

FIgURE 5: Relationship between brightness temperature $\left(T_{b}\right)$ and $H_{m 0}$ at 37 and $89 \mathrm{GHz}$ frequencies and horizontal $(\mathrm{H})$ and vertical (V) polarizations.

passive microwave emission of the ocean surface affect the $T_{b}$.

Although the $T_{b}$ depends on several other external factors (see Introduction), an increase in the surface area exposed to the sensor also contributes to a rise in $T_{b}$. Higher waves have a larger surface area, and the $\mathrm{H}$-polarization especially detects the associated rise in $T_{b}$. The passive microwave frequencies used in the study are sensitive to the individual contributions of small-scale features; for example, sea spray and whitecaps. However, at the observed Beaufort scale 0-5, sea sprays are not significant; thus, we assume the contribution of spray to modifying the $T_{b}$ as negligible. We observed an increase in $\mathrm{H}$ polarization $T_{b}$ at 37 and $89 \mathrm{GHz}$. This increase is consistent with the $\mathrm{H}$-polarization observations by previous researchers. $T_{b}$ increases with wind speed, foam, and whitecaps coverage at 8.36 and $19.34 \mathrm{GHz}$ frequencies $[9,44]$ and between 13.4 and $37 \mathrm{GHz}$ [45]. Other results illustrate a nonsignificant correlation between $T_{b}$ and wind speed at V-polarizations of $6.6,10.69$, and $37 \mathrm{GHz}$ frequencies [46]. In continuation of above studies, our results further confirm that the $T_{b}$ at $\mathrm{H}$ polarization is stronger than $T_{b}$ at $\mathrm{V}$-polarization at 37 and $89 \mathrm{GHz}$ under rougher conditions.

Backscatter is compared to $H_{m 0}$ and considered in the context of surface roughness at the $\mathrm{C}$-band scale. The interaction of incident radar waves with the capillary waves (millimeter level), whose restoring force is the surface tension of the water, is not accounted for, as the waves of this size are not detectable by the Waverider buoy. We compared the buoymeasured gravity waves, whose restoring force is gravity, with the backscatter. Kudryavtsev [47] has described the relationship between gravity (demonstrated as wave height) and capillary (demonstrated as Bragg scattering) waves. Figures 6(a) and 6(b) show the VV and HV backscatter at incidence angles $20^{\circ}, 30^{\circ}$, and $40^{\circ}$ for the three radar- $H_{m 0}$ cases. The plots include backscatter intensities to provide insight into the relative contributions of gravity and capillary waves. We observed a decrease in backscatter with the increasing incidence angle, as expected, over the sampled range. The highest intensities correspond to the highest $H_{m 0}$ on July 1 , though the weakest intensities correspond to the intermediate $H_{m 0}$ on July 9. Stronger $\mathrm{HH}$ (not shown), HV, and VV backscatter at all incidence angles for the lowest $H_{m 0}$ on July 26, relative to July 9, points to the likelihood of a stronger coupling of the radar waves to capillary waves, implying that higher capillary waves interaction with microwaves results in higher backscatter even at intermediate $H_{m 0}$.

Figures $7(\mathrm{a})$ and $7(\mathrm{~b})$ show the $\gamma_{\text {co }}$ and $\gamma_{\text {cross }}$ for each of the analyzed incidence angles and roughness conditions. If we consider the roughness, interpreted using the $\mathrm{HV}$ and $\mathrm{VV}$ intensities in Figure 6, instead of the measured $H_{m 0}$, the $\gamma_{\text {co }}$ at $20^{\circ}$ shows consistent behavior. The $\gamma_{\text {co }}$ shows an inverse relation to the radar-interpreted roughness in a manner consistent with Bragg and Integral Equation Model (IEM) surface backscattering models [48]. The $\gamma_{\text {co }}$ for given incidence angle and dielectric constant, according to Bragg and IEM theory, tends to zero (greater $\mathrm{HH}$ relative to VV) with increasing surface roughness provided that the surface roughness is greater than, or equal to the incident wavelength. The $\gamma_{\text {co }}$ is independent of surface roughness for smooth surfaces with surface height very small relative to the incident wavelength [38]. The additional $\mathrm{HH}$ backscatter relative to $\mathrm{VV}$ is so strong for the roughest $H_{m 0}$ case on July 1 that the ratio at $20^{\circ}$ becomes negative. For such a sea state, previous observations show greater $\mathrm{HH}$ backscatter sensitivity to the tilt modulation effect caused by larger waves on Bragg waves $[23,49]$, as well as wave breaking [50].

Our observations show correlation, which appears to be qualitatively proportionate, between $\gamma_{\text {co }}$ and $H_{m 0}$ at $40^{\circ}$ incidence angle; that is, $H_{m 0}$ and $\gamma_{c o}$ are much stronger on July 1 while July 9 and July 26 are similar. However, the results of Mouche et al. [24] show that one must consider azimuth angle (direction of waves relative to the radar look angle) at incidence angles larger than $25^{\circ}$. We have not considered it in the three cases evaluated in this study. In Figure 7(b), there is a significant increase in $\gamma_{\text {cross }}$ as a function of incidence angle and a small diversity between sea states. At $40^{\circ}$ incidence angle, there is an increase in the ratio of $2 \mathrm{~dB}$ between the smooth and rough $H_{m 0}$ cases, and the ratio shows correlation with the $H_{m 0}$. This effect is most likely because of the combined loss of $\mathrm{HV}$ backscatter with the incidence angle, which is also evident in Figure 6, coupled with an increased sensitivity of VV backscatter to the sea state. The HV intensity values are very low at incidence angles of $40^{\circ}$ and above, in the context of utilizing $\gamma_{\text {cross }}$ from spaceborne SAR and one must consider it relative to the noise equivalent sigma zero of the utilized sensor at a particular incidence angle.

Figures 8(a)-8(c) provide polarimetric coherence parameters $\rho_{\mathrm{HHVH}}, \rho_{\mathrm{VVHH}}$, and $\rho_{\mathrm{RRLL}}$ at each of the incidence angles and roughness conditions. Figure 8 (a) shows the $\rho_{\mathrm{HHVH}}$, a measure of the correlation between complex $\mathrm{HH}$ and $\mathrm{VH}$ returns. There appears to be no relationship between $\rho_{\mathrm{HHVH}}$ and $H_{m 0}$ under the constraints imposed in this study. However, the $\rho_{\mathrm{VVHH}}$ in Figure 8(b) shows an inverse relationship between the magnitude of the coherence and $H_{m 0}$ at $20^{\circ}$ 


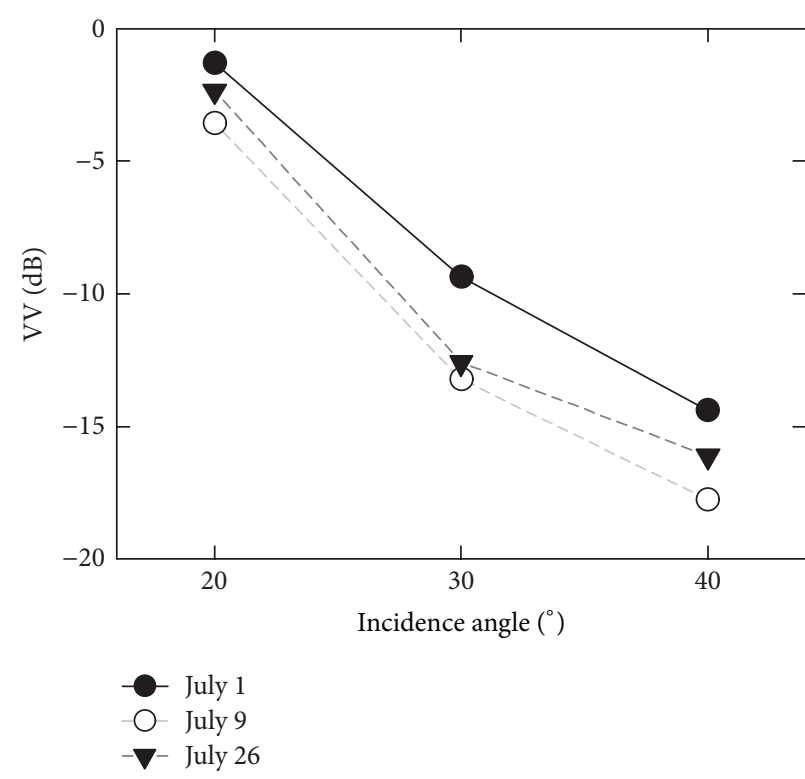

(a)

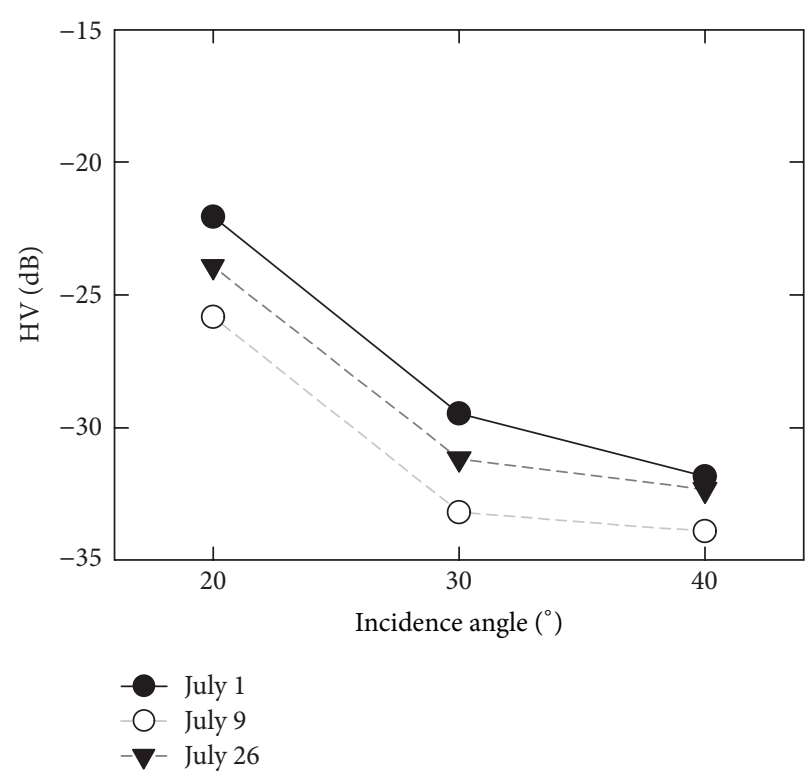

(b)

Figure 6: Incidence-angle-dependent (a) VV and (b) HV backscatter from wind-roughened open water on July $1\left(H_{m 0}=136 \mathrm{~cm}\right)$, July 9 $\left(H_{m 0}=66 \mathrm{~cm}\right)$, and July $26\left(H_{m 0}=47 \mathrm{~cm}\right)$.

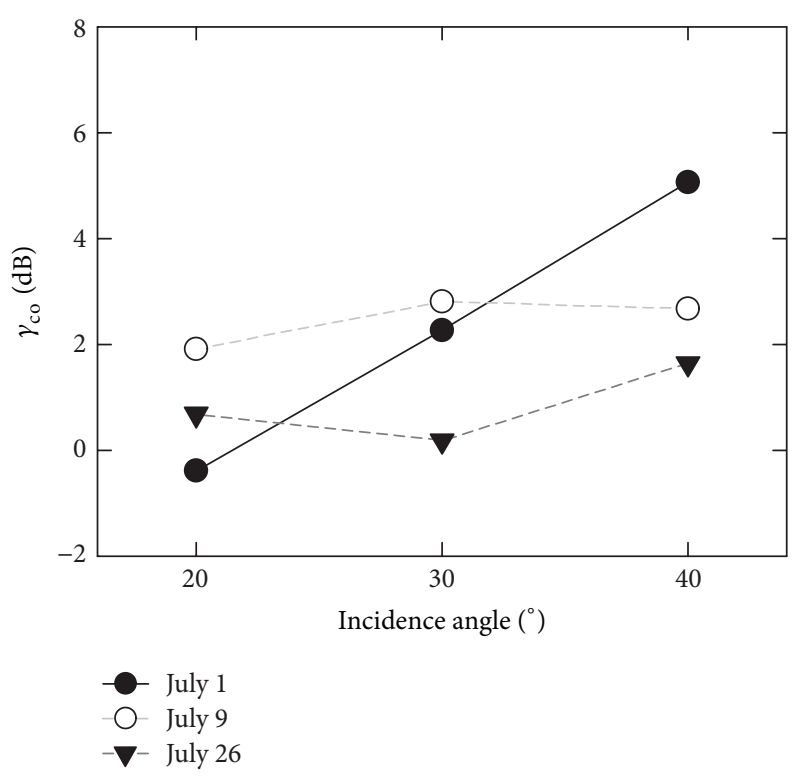

(a)

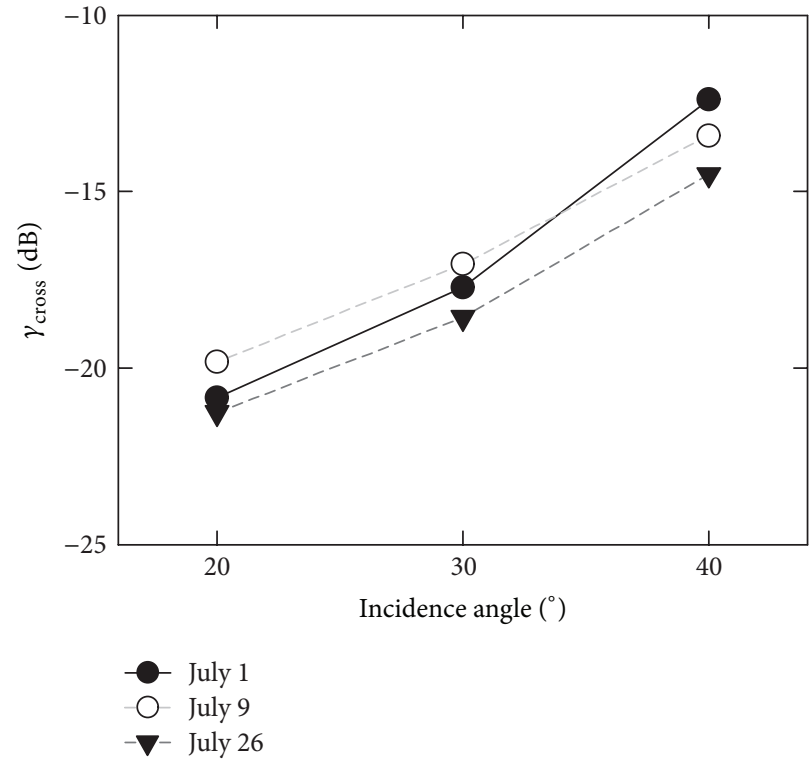

(b)

Figure 7: Incidence-angle-dependent ratios (a) $\gamma_{\text {co }}$ and (b) $\gamma_{\text {cross }}$ from wind-roughened open water on July $1\left(H_{m 0}=136 \mathrm{~cm}\right)$, July $9\left(H_{m 0}=\right.$ $66 \mathrm{~cm})$, and July $26\left(H_{m 0}=47 \mathrm{~cm}\right)$.

incidence angle. This is consistent with a depolarization of incident polarized radar energy induced by the rougher ocean waves. Beyond $20^{\circ}$, there is no discernible relationship between $H_{m 0}$ and $\rho_{\mathrm{VVHH}}$ that one can deduce based on expected scattering mechanisms. Similar magnitudes of the correlation coefficient are evident for sea states on July 9 and 26 . The rough sea state on July 1 (also seen at $20^{\circ}$ ) suggests that this parameter has utility for discriminating higher waves. One expects the parameter $\rho_{\text {RRLL }}$ in Figure 8(c) to be decreasing with increasing surface roughness $[34,38,51]$, though researchers developed it for terrestrial applications and did not verify for an ocean surface. At $20^{\circ}$, there is only a negligible decrease in $\rho_{\text {RRLL }}$ associated with the highest $H_{m 0}$ case on July 1 . The rougher sea state is linked with the highest $\rho_{\text {RRLL }}$ at incidence angles greater than $20^{\circ}$. This is contrary to previous results over terrestrial surfaces. An 


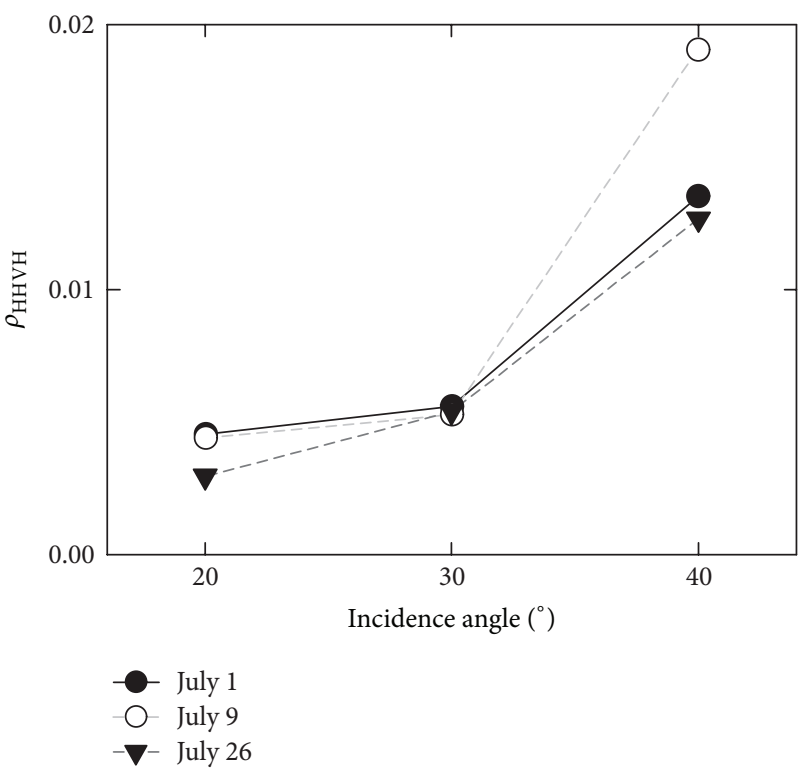

(a)

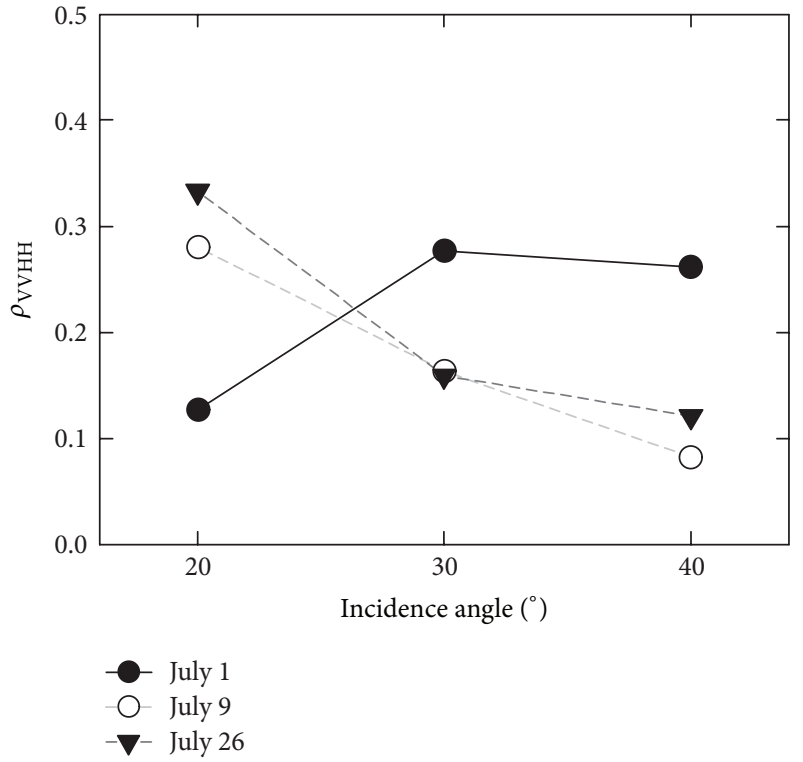

(b)

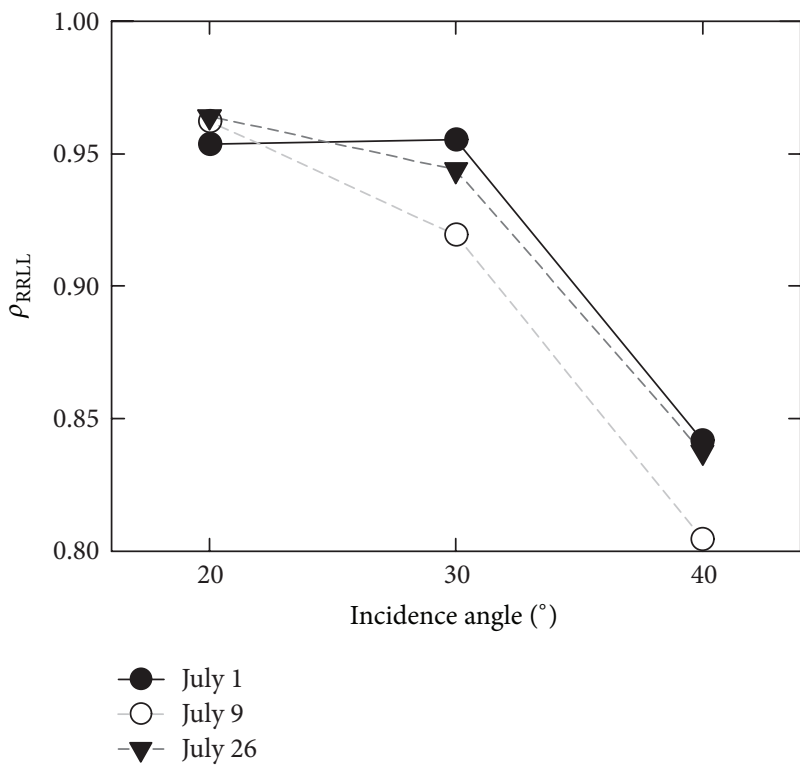

(c)

FIGURE 8: Incidence-angle-dependent polarimetric coherences (a) $\rho_{\mathrm{HHVH}}$ (b) $\rho_{\mathrm{VVHH}}$, and (c) $\rho_{\mathrm{RRLL}}$ from wind-roughened open water on July $1\left(H_{m 0}=136 \mathrm{~cm}\right)$, July $9\left(H_{m 0}=66 \mathrm{~cm}\right)$, and July $26\left(H_{m 0}=47 \mathrm{~cm}\right)$.

important consideration, however, is the scale of physical roughness, which is much greater for the ocean waves under investigation in this study. Furthermore, in a study of Jet Propulsion Laboratory (JPL) polarimetric scatterometer observations off the California coast at $13.4 \mathrm{GHz}$, Lee et al. [52] found an azimuthal dependency on the $\rho_{\text {RRLL }}$, but did not specify the incidence angle. The study of $\gamma_{\text {co }}$ by Keller et al. [22] (at C-band) mentioned above shows that one must consider the azimuth effect above $25^{\circ}$ for this coherence. The C-band radar observations in this study, particularly $\gamma_{\mathrm{co}}$, results in Figure 7(b), and the coherence results in Figures $8(\mathrm{a})-8(\mathrm{c})$, further support the need to consider ambiguity caused by the azimuth angle when considering the derivation of sea state from polarimetric radar data at incidence angles greater than $25^{\circ}$.

\section{Conclusions}

We presented, in this paper, passive microwave emission and polarimetric backscatter data coincident to wind and ocean buoy data at unique spatial and temporal scales relative to airborne and satellite remote sensing studies. A statistical analysis of coincident geophysical variables showed that the 
$T_{b}$ is more sensitive to $H_{m 0}$ than the wind speed at both $\mathrm{H}$ - and V-polarizations and that it shows stronger correlation with $H_{m 0}$ at $\mathrm{H}$-polarization. The PSD and $H_{m 0}$ show significant correlation with the $\mathrm{H}$-polarization of $T_{b}$ at both of the passive microwave frequencies (better with $37 \mathrm{GHz}$ because of longer wavelength) in this study. An assessment of C-band backscatter points to a dependency of HV and VV intensities on surface roughness, which is resonant to the radar frequency, but not captured by the Waverider buoy, as shown by greater backscatter intensities for the smoother $H_{m 0}$ (47 cm compared to $66 \mathrm{~cm}$ ) at each of the observed incidence angles. $\gamma_{\text {co }}$ and $\gamma_{\text {cross }}$ at $40^{\circ}$ are positively associated with $H_{m 0}$, and $\gamma_{\text {co }}$ particularly shows an increase that is proportional to $H_{m 0}$.

The polarimetric coherence parameter $\rho_{\mathrm{VvHH}}$ at $20^{\circ}$ also shows an inverse relationship with $H_{m 0}$ because of an expected decorrelation of complex returns with greater surface roughness. The $\rho_{\mathrm{VVHH}}$ also holds potential for discriminating rough $\left(H_{m 0}=136 \mathrm{~cm}\right)$ from smooth $\left(H_{m 0} \leq\right.$ $66 \mathrm{~cm}$ ) sea states at $30^{\circ}$ and $40^{\circ}$, based on an increase in the magnitude of $\rho_{\mathrm{VVHH}}$ with increasing $H_{m 0}$. We did not observe a decrease in $\rho_{\text {RRLL }}$ with increasing roughness, as expected for all incidence angles based on previous observations made over terrestrial surfaces. While the results presented here point to the utility of C-band satellite radar for deriving ocean surface physical roughness information without the need for wind speed or azimuth angle information at incidence angles less than approximately $25^{\circ}$, importantly they provide a stimulus for further investigations including the azimuth angle for observations above approximately $25^{\circ}$. With an increasing spatial and temporal coverage of open water in the Arctic, it will be important to develop robust satellite retrieval algorithms which examine both gas and energy exchange across the $\mathrm{AO}$ interface and into the marginal ice zones (MIZ) of the Arctic.

\section{Conflict of Interests}

The authors declare that there is no conflict of interests regarding the publication of this paper.

\section{Acknowledgments}

The authors are thankful to the crew of Canadian Research Icebreaker Amundsen for their cooperation in the acquisition of data. Mukesh Gupta thanks Debbie Armstrong and Natalie Asselin of University of Manitoba for help during buoy deployments. Randall K. Scharien would like to acknowledge Torsten Geldsetzer at the University of Calgary and Jim Mead at ProSensing, Inc. for their discussions and insights on the polarimetric scatterometer; also Dr. Klaus Hochheim and Natalie Asselin for their assistance in the field; and Tim Papakyriakou and Matthew Asplin for making available the meteorological data for this project. The Canadian International Polar Year (IPY) program office; the Natural Sciences and Engineering Research Council (NSERC); the Canada Research Chairs (CRC) Program; Canada Foundation for Innovation (CFI); and numerous international partner organizations which provided funding for the CFL project are acknowledged. The Canadian Northern Studies Trust (CNST); Maritime Awards Society of Canada Graduate Scholarships; and Margaret P. Hess Graduate Scholarship awards provided support to Randall K. Scharien. The authors dedicate this paper to the memory of their colleague Dr. Klaus Hochheim who lost his life while conducting sea ice research in the Canadian Arctic in September 2013.

\section{References}

[1] D. G. Barber and J. M. Hanesiak, "Meteorological forcing of sea ice concentrations in the southern Beaufort Sea over the period 1979 to 2000," Journal of Geophysical Research C, vol. 109, no. 6, Article ID C06014, 2004.

[2] J. V. Lukovich and D. G. Barber, "On sea ice concentration anomaly coherence in the southern Beaufort Sea," Geophysical Research Letters, vol. 32, no. 10, Article ID L10705, 2005.

[3] E. C. Carmack and R. W. Macdonald, "Oceanography of the Canadian shelf of the Beaufort Sea: a setting for marine life," Arctic, vol. 55, no. 1, pp. 29-45, 2002.

[4] W. O. Smith Jr. and D. G. Barber, Eds., Polynyas: Windows to the World, Elsevier, Amsterdam, The Netherlands, 2007.

[5] H. He and D. Chen, "Effects of surface wave breaking on the oceanic boundary layer," Geophysical Research Letters, vol. 38, no. 7, Article ID L07604, 2011.

[6] I. N. Esau, "Amplification of turbulent exchange over wide Arctic leads: large-eddy simulation study," Journal of Geophysical Research D, vol. 112, no. 8, Article ID D08109, 2007.

[7] K. St. Germain, G. A. Poe, and P. W. Gaiser, "Polarimetric emission model of the sea at microwave frequencies and comparison with measurements," Progress in Electromagnetics Research, vol. 37, pp. 1-30, 2002.

[8] S. H. Yueh, "Modeling of wind direction signals in polarimetric sea surface brightness temperatures," IEEE Transactions on Geoscience and Remote Sensing, vol. 35, no. 6, pp. 1400-1418, 1997.

[9] J. P. Hollinger, "Passive microwave measurements of sea surface roughness," IEEE Transactions on Geoscience Electronics, vol. 9, no. 3, pp. 165-169, 1971.

[10] F. T. Ulaby, R. K. Moore, and A. K. Fung, Microwave Remote Sensing: Active and Passive-Volume 3: Scattering and Emission Theory, Advanced Systems and Applications, Artech House, Dedham, Mass, USA, 1986.

[11] Y. A. Kravtsov and A. N. Churyumov, "Contribution of steep irregularities to the radio-brightness temperature of the ocean," Radiophysics and Quantum Electronics, vol. 43, no. 3, pp. 196201, 2000.

[12] E. C. Monahan and I. G. O'Muircheartaigh, "Whitecaps and the passive remote sensing of the ocean surface," International Journal of Remote Sensing, vol. 7, no. 5, pp. 627-642, 1986.

[13] A. E. Strong, "Mapping sea-surface roughness using microwave radiometry," Journal of Geophysical Research, vol. 76, no. 36, pp. 8641-8648, 1971.

[14] W. Nordberg, J. Conaway, D. B. Ross, and T. Wilheit, "Measurements of microwave emission from a foam-covered, winddriven sea," Journal of Atmospheric Sciences, vol. 28, no. 3, pp. 429-435, 1971.

[15] O. M. Phillips, "Radar returns from the sea surface-Bragg scattering and breaking waves," Journal of Physical Oceanography, vol. 18, no. 8, pp. 1065-1074, 1988. 
[16] D. Vandemark, B. Chapron, J. Sun, G. H. Crescenti, and H. C. Graber, "Ocean wave slope observations using radar backscatter and laser altimeters," Journal of Physical Oceanography, vol. 34, no. 12, pp. 2825-2842, 2004.

[17] H. Hersbach, "Comparison of C-Band scatterometer CMOD5.N equivalent neutral winds with ECMWF," Journal of Atmospheric and Oceanic Technology, vol. 27, no. 4, pp. 721-736, 2010.

[18] H. Hersbach, A. Stoffelen, and S. de Haan, "An improved C-band scatterometer ocean geophysical model function: CMOD5," Journal of Geophysical Research C, vol. 112, no. 3, Article ID C03006, 2007.

[19] A. S. Komarov, V. Zabeline, and D. G. Barber, "Ocean surface wind speed retrieval from C-band SAR images without input of wind direction," IEEE Transactions on Geoscience and Remote Sensing, vol. 52, no. 2, pp. 980-990, 2014.

[20] A. Stoffelen and D. Anderson, "Scatterometer data interpretation: measurement space and inversion," Journal of Atmospheric and Oceanic Technology, vol. 14, no. 6, pp. 1298-1313, 1997.

[21] W. L. Jones and L. C. Schroeder, "Radar backscatter from the ocean: dependence on surface friction velocity," BoundaryLayer Meteorology, vol. 13, no. 1-4, pp. 133-149, 1978.

[22] W. C. Keller, V. Wismann, and W. Alpers, “Tower-based measurements of the ocean $\mathrm{C}$ band radar backscattering cross section," Journal of Geophysical Research, vol. 94, no. 1, pp. 924930, 1989.

[23] D. R. Thompson, T. M. Elfouhaily, and B. Chapron, "Polarization ratio for microwave backscattering from the ocean surface at low to moderate incidence angles," in Proceedings of the IEEE International Geoscience and Remote Sensing Symposium (IGARSS '98), pp. 1671-1673, Seattle, Wash, USA, July 1998.

[24] A. A. Mouche, D. Hauser, J. Daloze, and C. Guérin, "Dualpolarization measurements at C-band over the ocean: results from airborne radar observations and comparison with ENVISAT ASAR data," IEEE Transactions on Geoscience and Remote Sensing, vol. 43, no. 4, pp. 753-769, 2005.

[25] V. Kudryavtsev, D. Hauser, G. Caudal, and B. Chapron, "A semiempirical model of the normalized radar cross-section of the sea surface 1. Background model," Journal of Geophysical Research C, vol. 108, no. 3, pp. FET 2-1-FET 2-24, 2003.

[26] V. Kudryavtsev, D. Hauser, G. Caudal, and B. Chapron, "A semiempirical model of the normalized radar cross section of the sea surface, 2. Radar modulation transfer function," Journal of Geophysical Research C, vol. 108, no. 3, pp. FET 3-1-FET 3-16, 2003.

[27] O. M. Phillips, "Spectral and statistical properties of the equilibrium range in the wind-generated gravity waves," Journal of Fluid Mechanics, vol. 156, pp. 505-531, 1985.

[28] G. R. Valenzuela, “Theories for the interaction of electromagnetic and oceanic waves-a review," Boundary-Layer Meteorology, vol. 13, no. 1-4, pp. 61-85, 1978.

[29] D. G. Barber, M. G. Asplin, Y. Gratton et al., "The international polar year (IPY) circumpolar flaw lead (CFL) system study: overview and the physical system," Atmosphere-Ocean, vol. 48, no. 4, pp. 225-243, 2010.

[30] K. Hunkins, "Waves on the Arctic Ocean," Journal of Geophysical Research, vol. 67, no. 6, pp. 2477-2489, 1962.

[31] L. D. Farmer, D. T. Eppler, and A. W. Lohanick, "Converting digital passive microwave radiances to Kelvin units of brightness temperatures," Technical Note 427, Naval Ocean Research and Development Activity (NORDA), Bay St. Louis, Miss, USA, 1990.
[32] D. Isleifson, B. Hwang, D. G. Barber, R. K. Scharien, and L. Shafai, "C-band polarimetric backscattering signatures of newly formed sea ice during fall freeze-up," IEEE Transactions on Geoscience and Remote Sensing, vol. 48, no. 8, pp. 3256-3267, 2010.

[33] T. Geldsetzer, J. B. Mead, J. J. Yackel, R. K. Scharien, and S. E. L. Howell, "Surface-based polarimetric C-band scatterometer for field measurements of sea ice," IEEE Transactions on Geoscience and Remote Sensing, vol. 45, no. 11, pp. 3405-3416, 2007.

[34] M. Gupta, R. K. Scharien, and D. G. Barber, "C-band polarimetric coherences and ratios for discriminating sea ice roughness," International Journal of Oceanography, vol. 2013, Article ID 567182, 13 pages, 2013.

[35] J.-S. Lee, D. L. Schuler, and T. L. Ainsworth, "Polarimetric SAR data compensation for terrain azimuth slope variation," IEEE Transactions on Geoscience and Remote Sensing, vol. 38, no. 5, pp. 2153-2163, 2000.

[36] D. L. Schuler, J.-S. Lee, D. Kasilingam, and G. Nesti, "Surface roughness and slope measurements using polarimetric SAR data," IEEE Transactions on Geoscience and Remote Sensing, vol. 40, no. 3, pp. 687-698, 2002.

[37] H. J. Eom and W.-M. Boerner, "Statistical properties of the phase difference between two orthogonally polarized SAR signals," IEEE Transactions on Geoscience and Remote Sensing, vol. 29, no. 1, pp. 182-184, 1991.

[38] I. Hajnsek, E. Pottier, and S. R. Cloude, "Inversion of surface parameters from polarimetric SAR," IEEE Transactions on Geoscience and Remote Sensing, vol. 41, no. 4, pp. 727-744, 2003.

[39] F. Mattia, T. L. Toan, J.-C. Souyris et al., "The effect of surface roughness on multifrequency polarimetric sar data," IEEE Transactions on Geoscience and Remote Sensing, vol. 35, no. 4, pp. 954-966, 1997.

[40] P. A. Hwang, M. A. Sletten, and J. V. Toporkov, "Analysis of radar sea return for breaking wave investigation," Journal of Geophysical Research C, vol. 113, no. 2, Article ID C02003, 2008.

[41] N. C. Wells, The Atmosphere and Ocean, John Wiley \& Sons, Oxford, UK, 2012.

[42] S. A. Kitaigorodskii, "Applications of the theory of similarity to the analysis of wind-generated wave motion as a stochastic process," Bulletin of the Academy of Sciences, USSR Geophysics Series, vol. 1, pp. 105-117, 1962.

[43] M. Donelan, M. Skafel, H. Graber, P. Liu, D. Schwab, and $\mathrm{S}$. Venkatesh, "On the growth rate of wind-generated waves," Atmosphere-Ocean, vol. 30, no. 3, pp. 457-478, 1992.

[44] J. P. Hollinger, "Passive microwave measurements of the sea surface," Journal of Geophysical Research, vol. 75, no. 27, pp. 5209-5213, 1970.

[45] A. Stogryn, "The emissivity of sea foam at microwave frequencies," Journal of Geophysical Research, vol. 77, no. 9, pp. 16581666, 1972.

[46] P. C. Pandey and R. K. Kakar, "An empirical microwave emissivity model for a foam-covered sea," IEEE Journal of Oceanic Engineering, vol. 7, no. 3, pp. 135-140, 1982.

[47] V. N. Kudryavtsev, "Physical model of the spectrum of capillarygravity waves," Physical Oceanography, vol. 8, no. 2, pp. 69-80, 1997.

[48] A. K. Fung and K. S. Chen, Microwave Scattering and Emission Models for Users, Artech House, Norwood, Mass, USA, 2010.

[49] D. B. Trizna and D. J. Carlson, "Studies of dual polarized low grazing angle radar sea scatter in nearshore regions," IEEE Transactions on Geoscience and Remote Sensing, vol. 34, no. 3, pp. 747-757, 1996. 
[50] H. Johnsen, G. Engen, and G. Guitton, "Sea-surface polarization ratio from envisat ASAR AP data," IEEE Transactions on Geoscience and Remote Sensing, vol. 46, no. 11, pp. 3637-3646, 2008.

[51] R. Touzi, W. M. Boerner, J. S. Lee, and E. Lueneburg, "A review of polarimetry in the context of synthetic aperture radar: concepts and information extraction," Canadian Journal of Remote Sensing, vol. 30, no. 3, pp. 380-407, 2004.

[52] J.-S. Lee, S. H. Yueh, and D. L. Schuler, "Polarimetric analysis of scatterometer data for ocean surface wind measurement," in Proceedings of the IEEE International Geoscience and Remote Sensing Symposium (IGARSS '04), vol. 1, pp. 20-24, Anchorage, Alaska, USA, September 2004. 

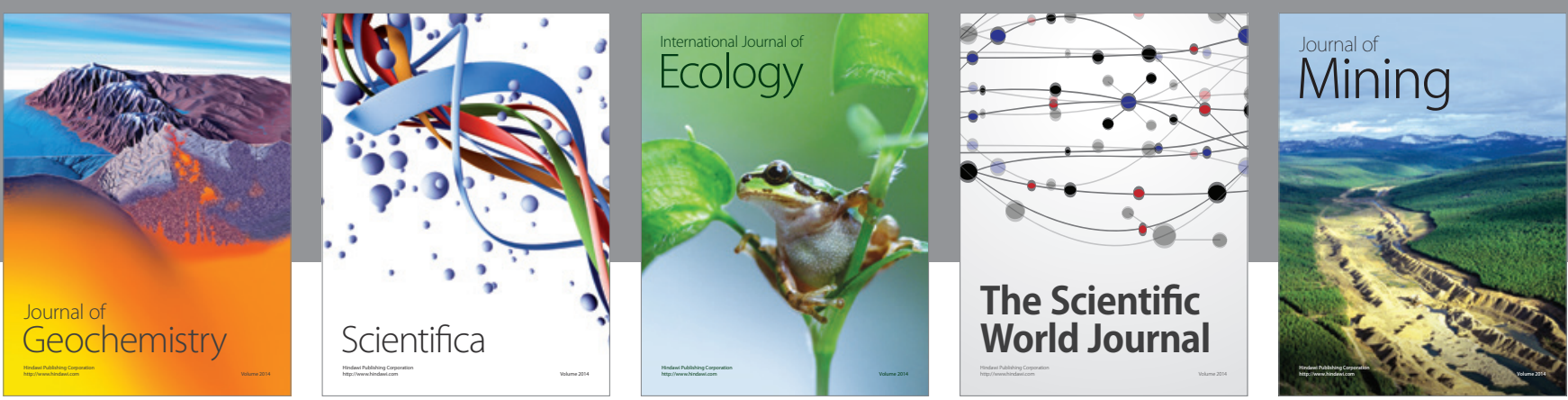

The Scientific World Journal
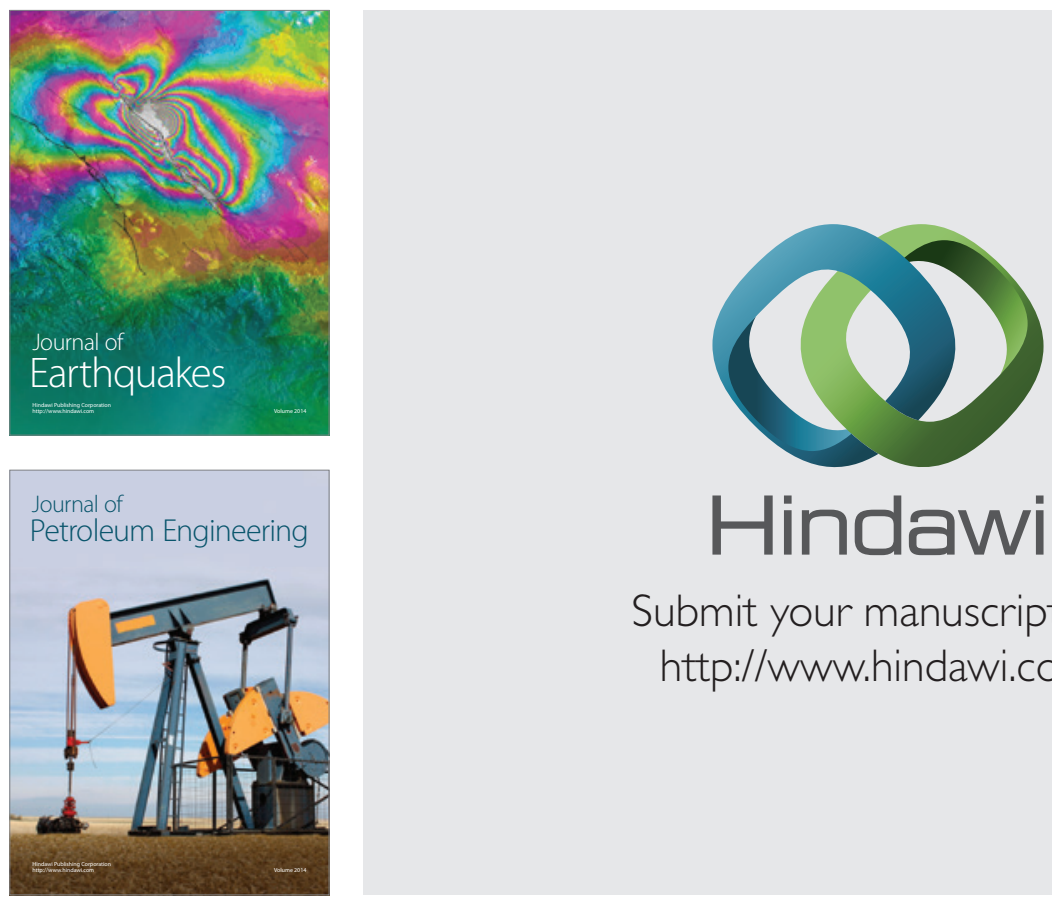

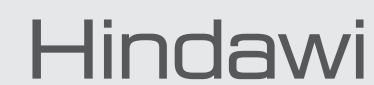

Submit your manuscripts at

http://www.hindawi.com
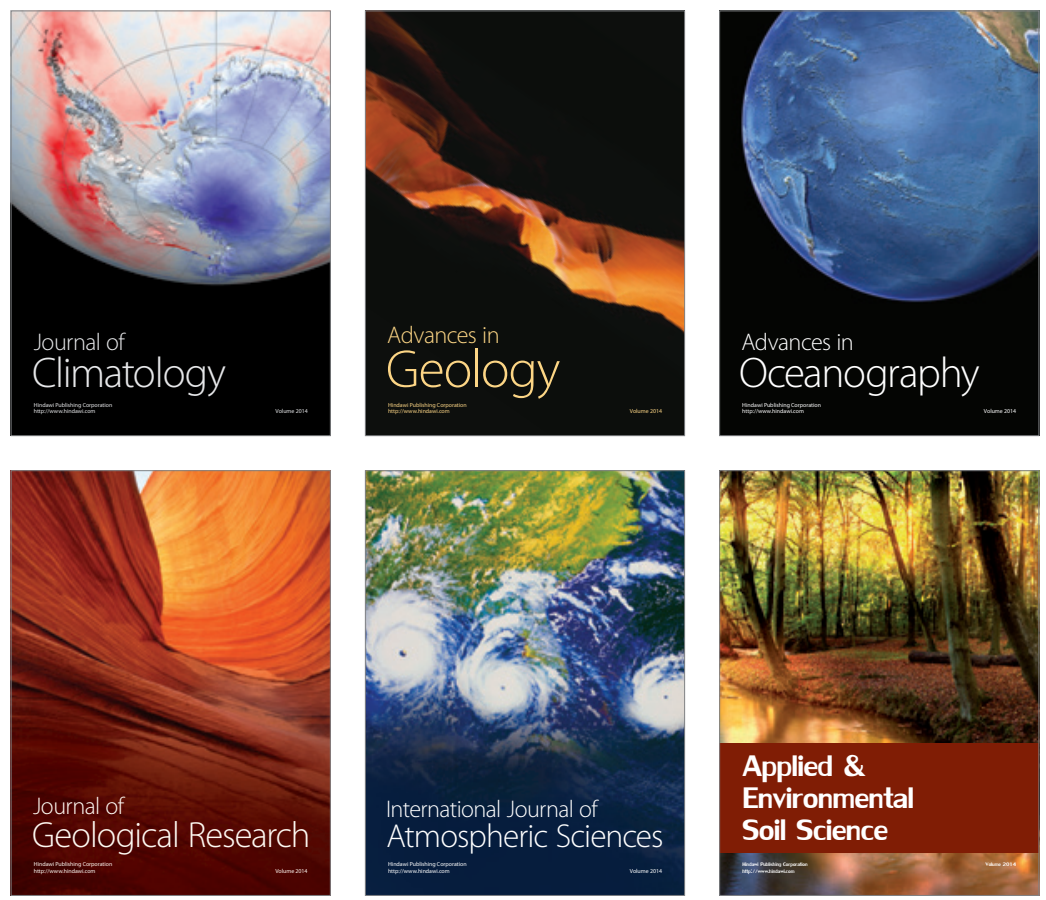
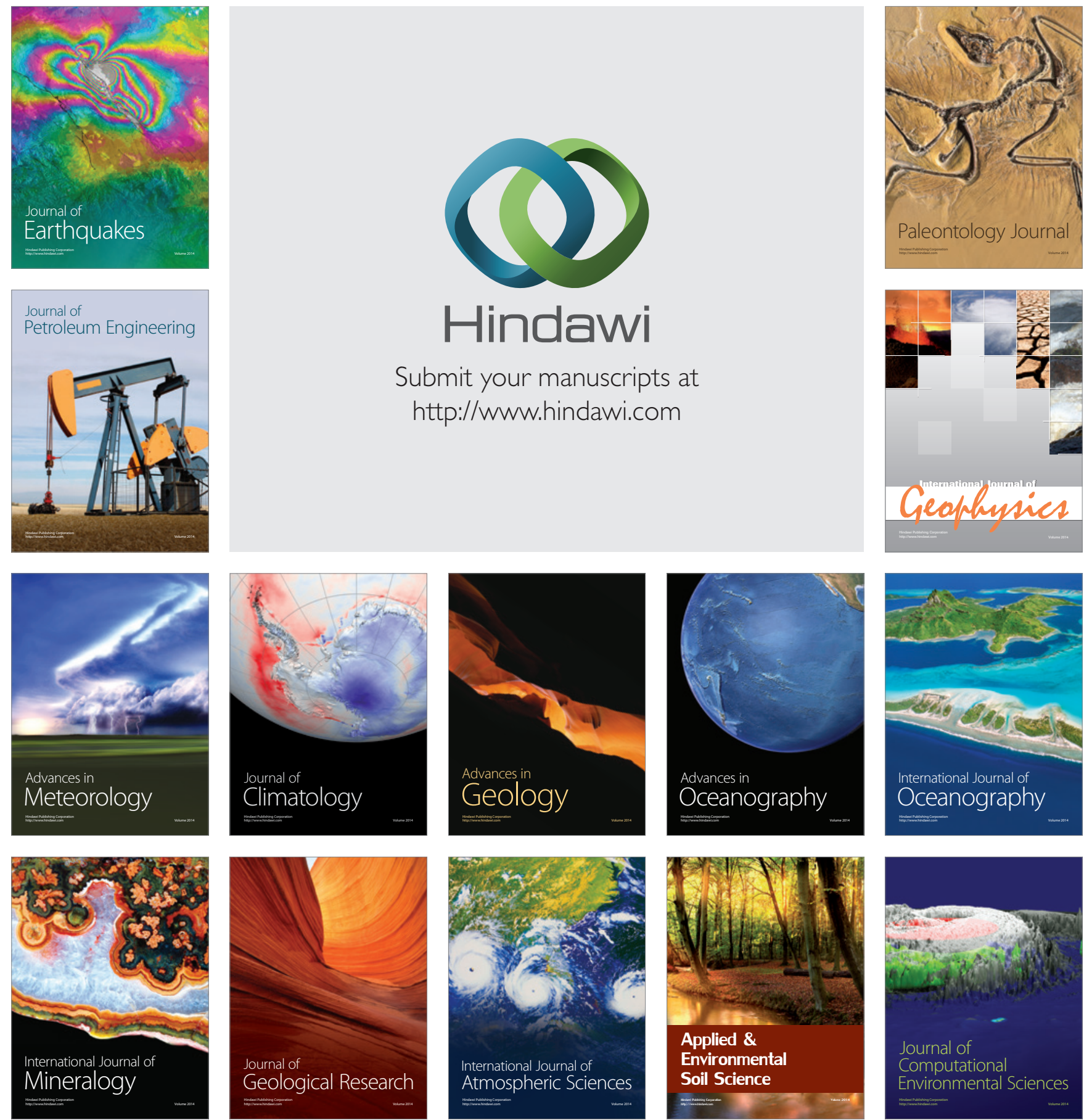